\title{
Validitas dan Praktikalitas Permainan Kartu Kimia (c-Card) pada Materi Sistem Koloid sebagai Media Pembelajaran kelas XI SMA/MA
}

\section{The Validation and Practicality} of Chemical Card Game on Colloidal System Materials as A Learning Media on In Second Grade of Senior High School

\author{
A Zebina ${ }^{1}$ and Bayharti ${ }^{*}$ \\ ${ }^{1}$ Pendidikan Kimia, Universitas Negeri Padang, Jl. Prof. Dr. Hamka, Air Tawar Barat, \\ Padang Utara, Sumatera Barat, Indonesia 25171 \\ *chembayharti@gmail.com
}

\section{ARTICLE INFO}

Received 31 December 2019

Revised 18 January 2020

Published 06 February 2020

\begin{abstract}
The purpose of the research to develop learning media for chemical card games (C-Card) on colloidal system materials for grade XI SMA / MA and determine the level of validity and practicality of the developed media. This research uses a 4-D model which consists of 4 stages, namely definition, design, development and dissemination. The resulting media was validated by two chemistry lecturers at the faculty of mathematics and natural sciences UNP and also by the two chemistry teachers at SMAN 1 Batang Anai. Through a validation questionnaire, the validation value of kappa moment obtained was 0.85 with a very high category and value of the practicality of teachers and students was 0,88 with very high categories an 0.80 with high categories. It can be concluded that the chemical card game media is valid and practical.
\end{abstract}

\section{KEYWORDS}

Chemical Card Games, Colloidal System, Research and Development, 4-D Models

\begin{abstract}
ABSTRAK
Tujuan dilakukannya penelitian ini yaitu untuk mengembangkan media pembelajaran Permainan Kartu Kimia (C-Card) pada materi sistem koloid kelas XI SMA/MA serta menentukan nilai praktikalitas dan validitas dari media yang dikembangkan. Penelitian ini dilakukan dengan menggunakan model 4-D yang terdiri dari 4 tahapan yaitu pendefinisian, perancangan, pengembangan dan penyebaran. Media yang dihasilkan akan dilakukan validasi oleh dua orang dosen Kimia FMIPA UNP dan dua orang guru Kimia SMAN 1 Batang Anai. Dengan menggunakan instrumen angket, didapatkan nilai Momen Kappa validasi 0,85 serta nilai praktikalitas guru dan siswa 0,88 dan 0,80 . Dapat disimpulkan bahwa media permainan kartu kimia sudah valid dan praktis.
\end{abstract}

KATA KUNCI

Permainan Kartu Kimia, Sistem Koloid, Research and Development, Model 4-D 


\section{PENDAHULUAN}

Salah satu pokok pembahasan yang dipelajari di kelas XI SMA/MA adalah materi sistem koloid. Materi ini termasuk materi yang menarik, karena dalam kehidupan sehari-hari sangat mudah ditemukan aplikasi dari materi sistem koloid. Materi sistem koloid mengandung fakta, konsep, serta prosedur. Berdasarkan karakteristik materi tersebut, siswa dituntut untuk lebih banyak membaca, berdiskusi dan mengerjakan soal latihan agar tercapainya tujuan pembelajaran, sehingga untuk meningkatkan penguasaan siswa mengenai konsep, prinsip, dan prosedural yang telah dipelajari maka perlu dilakukan latihan ${ }^{[1]}$.

Dilihat dari angket wawancara yang dilakukan dengan seorang guru SMAN 1 Payakumbuh dan SMAN 1 Batang Anai, didapatkan informasi dalam proses pembelajaran guru telah menggunakan media pada proses pembelajaran. Media yang digunakan yaitu LKS (lembar kerja siswa), media bergambar serta media powerpoint (PPT). Proses pembelajaran yang berlangsung masih bersifat meneruskan informasi dengan guru berceramah di depan kelas. Jika guru selesai menjelaskan materi, peserta didik ditugaskan untuk menjawab pertanyaan yang terdapat di buku paket ataupun di LKS. Latihan tersebut cenderung bersifat individual, tidak bervariasi, tidak mempunyai sifat kompetisi sehingga membuat siswa menjadi kurang aktif dan merasa bosan saat mengerjakan soal latihan ${ }^{[2]}$.

Berdasarkan hasil angket yang diisi oleh 32 orang siswa kelas XI SMAN 1 Payakumbuh dan 30 orang peserta didik kelas XII SMAN 1 Batang Anai, diperoleh informasi bahwa dalam mengerjakan soal latihan mereka cenderung mengerjakan secara individu. Soal yang diberikan tidak bersifat kompetitif, sehingga rendahnya aktivitas siswa dalam mengerjakan latihan. Ini tentu bertolak belakang dengan karakteristik peserta didik yang suka bermain, suka berdiskusi dan berkelompok. Pada proses pembelajaran siswa lebih menyukai media permainan digunakan saat proses pembelajaran. Menurut UNESCO (1988) bahwa usia 7-18 tahun cenderung menyukai permainan dalam kegiatan pembelajaran. Untuk itu dalam proses pembelajaran dibutuhkan suatu media pembelajaran yang menarik perhatian siswa melalui media permainan ${ }^{[3]}$.

Permainan edukatif (Game Educative) dapat melibatkan peserta didik menjadi aktif, memunculkan rasa gembira, dan menambah motivasi untuk mengetahui materi yang sedang dipelajari ${ }^{[4]}$. Tidak hanya itu, media pembelajaran dalam bentuk media permainan berfungsi untuk membuat siswa belajar berkelompok, menumbuhkan jiwa kompetitif, sehingga dalam proses belajar suasana menjadi menyenangkan ${ }^{[5]}$. Permainan kartu kimia dapat menarik minat siswa, sehingga dalam proses pembelajaran siswa menjadi lebih aktif. Dilihat dari analisis angket, menunjukkan bahwa siswa tertarik dengan permainan kartu kimia untuk dijadikan sebagai media pembelajaran dalam materi sistem koloid.

Berdasarkanuraiandiatas, untukmemantapkan konsep peserta didik dan meningkatkan aktivitas siswa dalam mengerjakan latihan pada proses pembelajaran, maka penulis tertarik untuk mengembangkan media pembelajaran berupa permainan Kartu Kimia ( $C$-Card) serta menentukan tingkat validitas dan tingkat praktikalitas dari media tersebut.

\section{METODE}

Penelitian yang dilakukan termasuk ke dalam jenis R\&D (Research and Development). Dimana akan menghasilkan sebuah produk permainan kartu kimia pada materi sistem koloid kelas XI SMA/MA. Model pengembangan yang digunakan yaitu Four-D models.

Penelitian dilakukan untuk merancang dan mengembangkan media alternatif yaitu media Permainan Kartu Kimia (C-Card) yang valid dan praktis yang dapat digunakan untuk membuat aktivitas siswa menjadi meningkatkan khususnya dalam mengerjakan latihan dan untuk pemantapan konsep peserta didik pada materi Sistem Koloid. Adapun objek pada penelitian ini yaitu Permainan Kartu Kimia (C-Card) sebagai media pembelajaran pada materi Sistem Koloid.

Penelitian ini menggunakan instrumen angket validitas dan angket praktikalitas yang akan diisi oleh responden. Angket tersebut digunakan untuk mengetahui tingkat validitas dan praktikalitas dari media yang dikembangkan. Pada pengolahan data menggunakan teknik data deskriptif yang mendeskripsikan tingkat validitas dan praktikalitas dari media yang dikembangkan. Setelah data diperoleh, maka akan diolah menggunakan rumus Kappa Cohen, yang akan menghasilkan nilai Momen Kappa. Adapun rumus dari Momen Kappa sebagai berikut:

$$
\text { momen kappa }(k)=\frac{\rho_{0}-\rho_{e}}{1-\rho_{e}}
$$

Keterangan:

$\mathrm{k}=$ nilai momen kappa

$\rho_{e}=$ proporsi yang terealisasi

$\rho_{0}=$ proporsi yang tidak terealisasi

\section{HASIL DAN DISKUSI}

\subsection{Tahap Pendefinisian (define)}

\subsubsection{Analisis Ujung Depan.}

Analisis ini dilakukan untuk memunculkan dan menetapkan permasalahan dasar yang dihadapi guru dan peserta didik dalam proses pembelajaran khususnya dalam materi sistem koloid.

\subsubsection{Analisis Siswa.}

Analisis siswa bertujuan untuk mengetahui dan menelaah karakteristik peserta didik. Analisis peserta didik dilakukan dengan mewawancarai guru kimia mengenai karakteristik peserta didik 
serta menyebarkan angket kepada masing-masing peserta didik.

\subsubsection{Analisis Tugas.}

Tahap ini bertujuan untuk merinci materi ajar secara garis besar. Analisis tugas pada materi sistem sistem koloid menurut kurikulum 2013 dilakukan dengan cara menganalisis Kompetensi Inti (KI) dan Kompetensi dasar (KD) yang dijabarkan menjadi Indikator Pencapaian Kompetensi (IPK).

\subsubsection{Analisis Konsep.}

Tahap ini merupakan identifikasi, merinci dan menyusun secara sistematis konsep-konsep utama pada materi sistem koloid.

\subsubsection{Analisis Tujuan Pembelajaran.}

Langkah ini dilakukan untuk mengkonversikan hasil yang telah diperoleh pada tahap analisis tugas dan analisis konsep menjadi tujuan pembelajaran.

\subsection{Tahap Perancangan (design)}

Perancangan (design) adalah tahap yang digunakan untuk merancang media pembelajaran yang dikembangkan yaitu Permainan Kartu Kimia (C-Card) pada materi sistem koloid. Satu set permainan kartu kimia ini terdiri dari 55 lembar kartu bermain yang berisikan pertanyaan dari materi sistem koloid, lembar penilaian, lembar aturan permainan, lembar kunci jawaban.

Kartu bermain kimia didesain dengan menggunakan empat jenis warna yang berbeda yaitu hijau, merah, oren dan biru. Selain diberi warna yang berbeda, kartu bermain juga ditambahkan gambar yang berkaitan dengan kimia untuk menjadikan kartu lebih menarik. Gambar kartu bermain dapat dilihat pada Gambar 1.

Lembar kunci jawaban dari kartu kimia berisikan jawaban dari setiap pertanyaan yang ada pada kartu bermain. Koordinator akan mengkoreksi setiap jawaban yang dijawab oleh para pemain, dan menuliskan nilainya pada lembar penilaian. Lembar kunci jawaban permainan kartu kimia dapat dilihat pada Gambar 2.

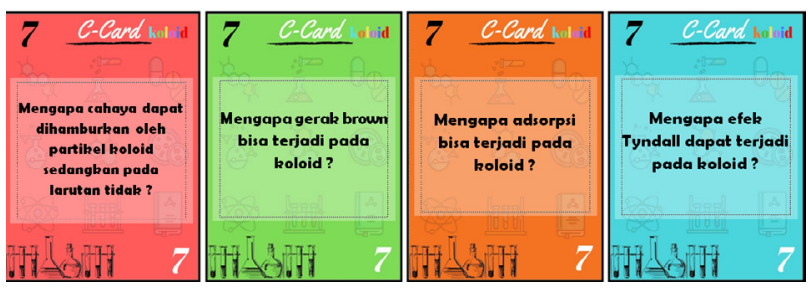

Gambar 1. Kartu Kimia

Koordinator menuliskan nilai yang didapatkan oleh masing-masing pemain pada lembar penilaian. Jika pemain menjawab dengan benar, maka pemain tersebut mendapatkan poin 4 , jika pemain tidak menjawab ataupun jawaban yang diberikan salah, maka pemain mendapatkan poin -1. Adapun lembar penilaian dapat dilihat pada Gambar 3 .

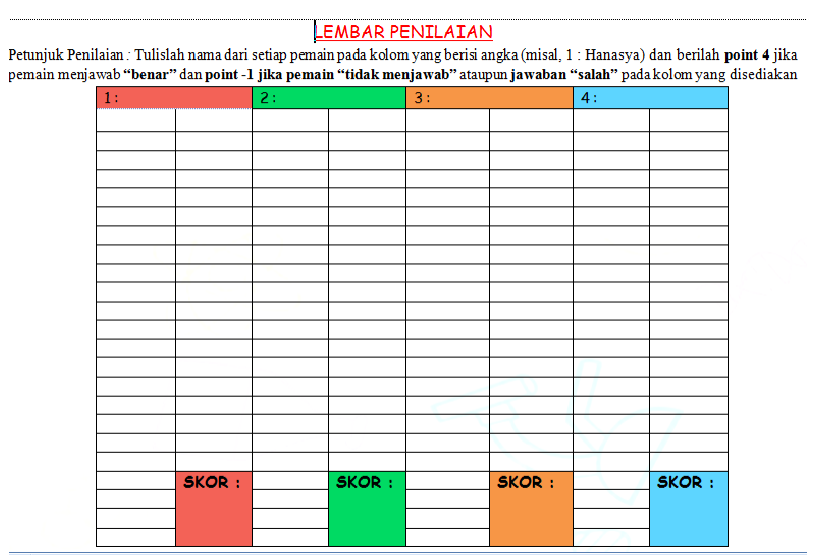

\section{Gambar 3. Lembar Penilaian Permainan Kartu Kimia}

Selain itu, juga terdapat lembar aturan permainan yang berisikan aturan dan ketentuan yang harus dipenuhi oleh para pemain. Lembar aturan permainan dapat dilihat pada Gambar 4.

\begin{tabular}{|c|c|c|c|c|}
\hline & RED & GREEN & ORANGE & BLUE \\
\hline As & Suspensi-koloid- larutan & Suspensi dan koloid & Suspensi dan larutan & Koloid dan suspensi \\
\hline $\mathbf{K}$ & Koloid dan larutan & Larutan dan koloid & Koloid dan larutan & Larutan dan koloid \\
\hline $\mathbf{2}$ & Emulsi cair & Emulsi padat & Aerosol cair & Sol cair \\
\hline $\mathbf{J}$ & Emulsi padat & Busa padat & Emulsi cair & Emulsi padat \\
\hline 10 & $\begin{array}{l}\text { medium pendispersi padat dan fase terdispersi } \\
\text { cair }\end{array}$ & $\begin{array}{l}\text { medium pendispersi cair dan fase } \\
\text { terdispersi padat }\end{array}$ & $\begin{array}{l}\text { medium pendispersi padat dan fase } \\
\text { terdispersi padat }\end{array}$ & $\begin{array}{l}\text { medium pendispersi gas dan fase } \\
\text { terdispersi cair }\end{array}$ \\
\hline 9 & cair-cair & cair-gas & gas-padat & cair-cair \\
\hline 8 & $\begin{array}{l}\text { Efek Tyndall atau peristiwa penghamburan } \\
\text { cahaya oleh partikel koloid }\end{array}$ & $\begin{array}{c}\text { Gerak Brown atau gerakan zig zag } \\
\text { oleh partikel koloid }\end{array}$ & $\begin{array}{l}\text { Adsorpsi atau peristiwa penyerapan } \\
\text { muatan pada permukaan koloid }\end{array}$ & $\begin{array}{l}\text { Elektroforesis atau pergerakan partikel } \\
\text { koloid dibawah pengaruh medan listrik }\end{array}$ \\
\hline 7 & $\begin{array}{l}\text { Karena partikel koloid berukuran lebih } \\
\text { besar daripada ukuran partikel larutan, } \\
\text { sehingga partikel koloid mampu } \\
\text { menghamburkan cahaya kesegala arah. }\end{array}$ & $\begin{array}{c}\text { Karena adanya tumbukan antara } \\
\text { partikel koloid dalam medium } \\
\text { pendispersinya. }\end{array}$ & $\begin{array}{l}\text { Karena terjadinya penyerapan molekul, ion } \\
\text { ataupun atom dengan partikel koloid }\end{array}$ & $\begin{array}{c}\text { Karena ukuran partikel koloid mampu } \\
\text { menghamburkan cahaya yang disebut } \\
\text { dengan efek Tyndall (peristiwa } \\
\text { penghamburam cahaya) }\end{array}$ \\
\hline 6 & Efek tyndall & Koagulasi & Dialisis & Adsorpsi \\
\hline 5 & $\begin{array}{l}\text { Koloid yang fase terdispersimya suka } \\
\text { menarik medium pendispersi }\end{array}$ & $\begin{array}{l}\text { Koloid yang fase terdispersimya tidak } \\
\text { suka menarik medium pendispersi }\end{array}$ & $\begin{array}{c}\text { Koloid yang fase terdispersimya suka } \\
\text { menarik air }\end{array}$ & $\begin{array}{c}\text { Koloid yang fase terdispersimya tidak } \\
\text { suka menarik air }\end{array}$ \\
\hline 4 & $\begin{array}{l}\text { Fase terdispersi pada koloid liofob apabila } \\
\text { sudah menggumpal sulit diubah kembali }\end{array}$ & $\begin{array}{l}\text { Fase terdispersi pada koloid liofil } \\
\text { apabila sudah menggumpal dapat }\end{array}$ & $\begin{array}{l}\text { Karena koloid hidrofil terdapat gugus } \\
\text { polar pada permukaannnya, sehingga }\end{array}$ & $\begin{array}{l}\text { Karena koloid hidrofil tidak terdapat } \\
\text { gugus polar pada permukaannnya, }\end{array}$ \\
\hline
\end{tabular}

Gambar 2. Lembar Kunci Jawaban Permainan Kartu Kimia 


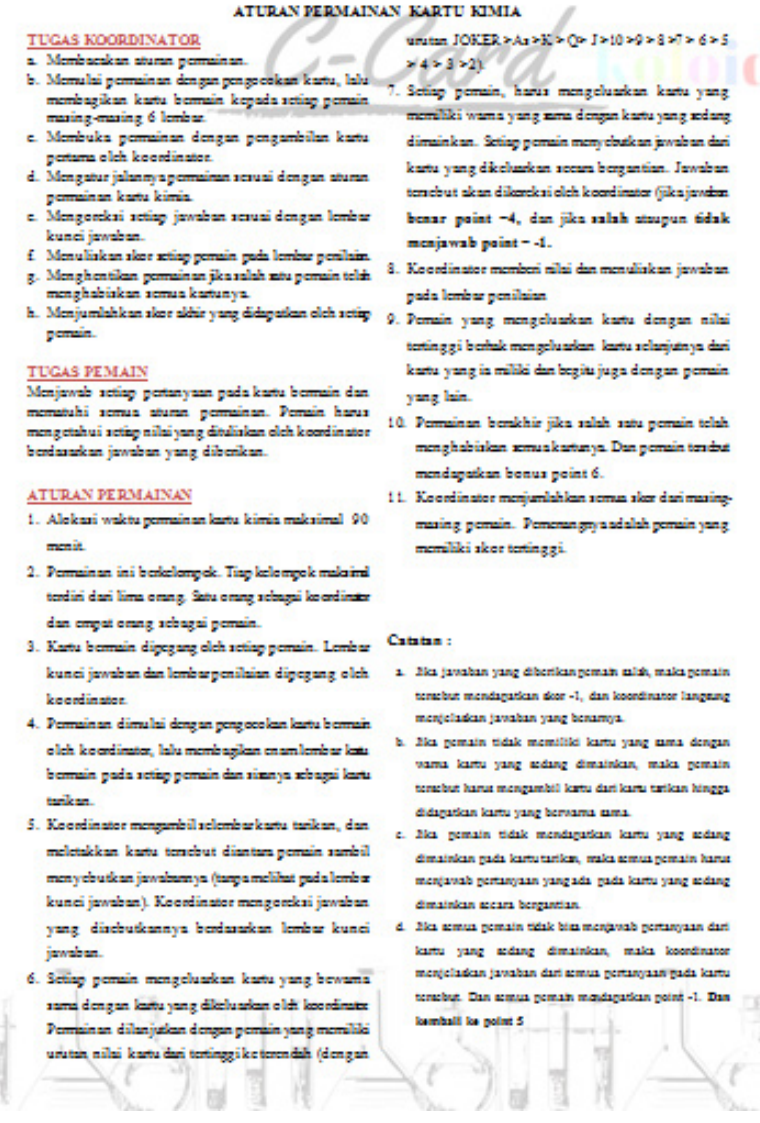

Gambar 4. Lembar Aturan Permainan Kartu Kimia

\subsection{Tahap Pengembangan (Develop)}

Tahap ini dilakukan dengan merevisi media berdasarkan kritik dan saran dari responden terhadap media yang dikembangkan, sehingga dihasilkan media yang lebih baik dari sebelumnya.

\subsubsection{Uji Validitas.}

Uji ini dilakukan untuk mengetahui bahwa produk yang dikembangkan telah valid. Validasi ini dilakukan oleh dua orang Dosen Kimia FMIPA UNP Dan dua orang Guru Kimia SMAN 1 Batang Anai. Tingkat validitas produk dilihat dari empat fungsi media, yaitu fungsi kognitif, fungsi afektif, fungsi atensi dan fungsi kompensatoris. Hasil analisis uji validitas dapat dilihat pada Gambar 5.

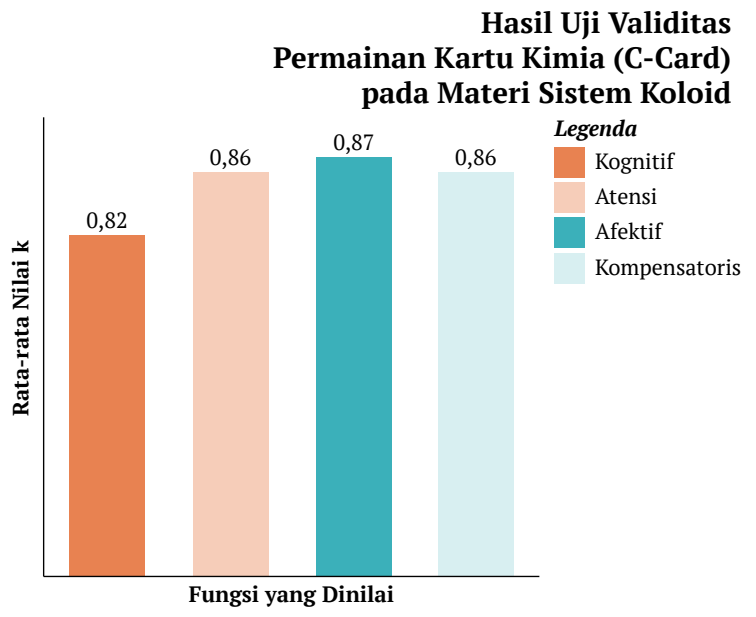

Gambar 5. Hasil Uji Validitas Permainan Kartu Kimia

\subsubsection{Uji Praktikalitas.}

Uji ini dilakukan untuk mengetahui tingkat kepraktisan dari media permainan kartu kimia berdasarkan kemudahan dari penggunaannya dan efisiensi dari waktu yang digunakan. Penentuan tingkat kepraktisan media dilakukan dengan menyebarkan angket kepada dua guru kimia SMAN 1 Batang Anai dan 32 orang siswa kelas XII IPA 1 SMAN 1 Batang Anai. Hasil analisis uji praktikalitas yang dilakukan guru dan siswa dapat dilihat pada Gambar 6.

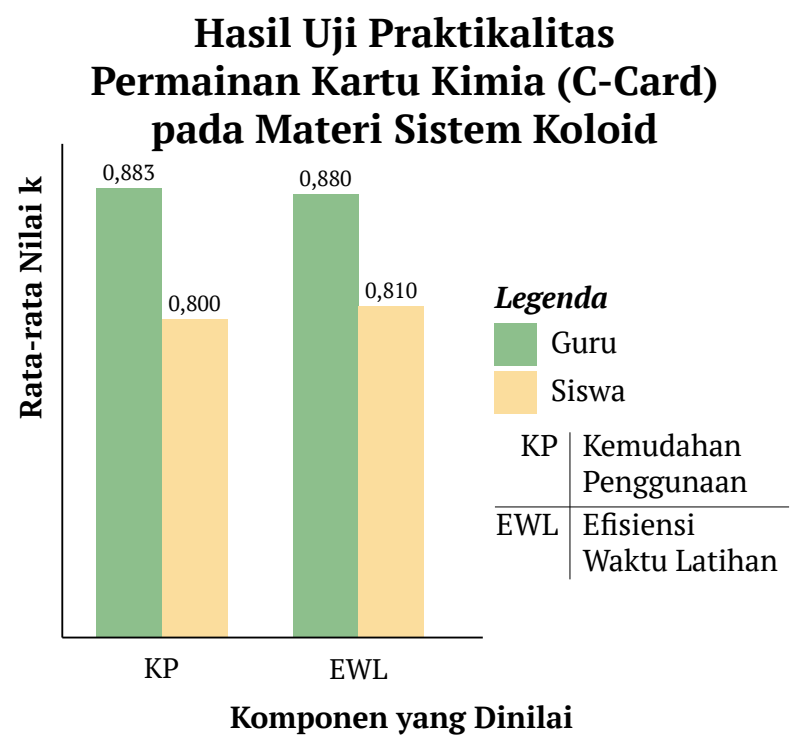

Gambar 6. Hasil Uji Praktikalitas Permainan Kartu Kimia

\subsection{Pembahasan}

\subsubsection{Penentuan Tingkat Validitas}

\subsubsection{Fungsi Kognitif.}

Fungsi ini berkaitan dengan bagaimana suatu media bisa membantu siswa dalam pencapaian tujuan pembelajaran serta membantu dalam mengingat serta memahami informasi yang ada pada media tersebut ${ }^{[6]}$. Setelah dilakukan olah data validasi terhadap nilai kognitif didapatkan momen kappa media permainan kartu kimia yaitu 0,82 dengan tingkat sangat tinggi. Artinya media yang dikembangkan dapat membantu peserta didik untuk lebih memahami konsep pembelajaran, sehingga Indikator Pencapaian Kompetensi pembelajaran tercapai. Hal ini menunjukkan bahwa Permainan Kartu Kimia yang dikembangkan telah memenuhi fungsi kognitif dari suatu media pembelajaran, dengan kategori validitas sangat tinggi, karena media permainan kartu kimia dapat membantu siswa dalam memahami dan mengingat informasi dari media yang digunakan dalam proses pembelajaran, sehingga media ini dapat digunakan sebagai media pembelajaran pada materi Sistem Koloid.

\subsubsection{Fungsi Atensi.}

Fungsi atensi berkaitan dengan dengan bagaimana suatu media dapat menarik dan mengarahkan perhatian siswa untuk dapat fokus 
terhadap materi pembelajaran ${ }^{[6]}$. Setelah dilakukan analisis data validasi terhadap fungsi atensi media Permainan Kartu Kimia, didapatkan nilai Momen Kappa yaitu 0,86 dengan tingkat sangat tinggi. Artinya media Permainan Kartu Kimia dapat menarik dan mengarahkan perhatian peserta didik untuk bisa berkonsentrasi pada materi sistem koloid. Hal ini menunjukkan bahwa Permainan Kartu Kimia yang dikembangkan sudah memenuhi fungsi atensi dari suatu media pembelajaran, dengan tingkat validitas sangat tinggi, sehingga media ini dapat digunakan pada materi sistem koloid sebagai media pembelajaran.

\subsubsection{Fungsi Afektif.}

Fungsi afektif berkaitan dengan bagaimana suatu media dapat menggugah sikap serta emosi peserta didik terhadap informasi yang ditampilkan ${ }^{[6]}$. Hal ini ditunjukkan dari bagaimana peserta didik menikmati kegiatan pembelajaran misalnya seperti membaca teks yang bergambar. Berdasarkan hasil analisis data dari penilaian validator terhadap fungsi afektif media Permainan Kartu Kimia, didapatkan nilai Momen Kappa yaitu 0,87 dengan tingkat sangat tinggi. Artinya, media Permainan Kartu Kimia menarik perhatian siswa dalam proses belajar, sehingga peserta didik bersikap kompetitif atau saling berlomba untuk mendapatkan poin atau nilai tertinggi dalam Permainan Kartu Kimia pada materi Sistem Koloid. Artinya Permainan Kartu Kimia yang dikembangkan sudah memenuhi fungsi afektif dari suatu media pembelajaran, dengan kategori validitas sangat tinggi, sehingga media ini dapat digunakan pada materi sistem koloid sebagai media pembelajaran .

\subsubsection{Fungsi Kompensatoris.}

Fungsi ini berkaitan dengan bagaimana suatu media dapat membantu peserta didik yang lemah dan lambat agar menjadi lebih mudah memahami materi pembelajaran ${ }^{[6]}$. Berdasarkan hasil analisis data penilaian dari validator didapatkan Momen Kappa yaitu 0,86 dengan kategori sangat tinggi. Artinya soal-soal yang ada pada media Permainan Kartu Kimia dapat membantu peserta didik yang lemah dan lambat menjadi lebih paham dalam memahami materi Sistem Koloid. Hal ini menunjukkan bahwa media Permainan Kartu Kimia yang dikembangkan telah memenuhi fungsi kompensatoris dari suatu media pembelajaran, dengan kategori validitas sangat tinggi, sehingga media ini dapat digunakan sebagai media pembelajaran pada materi Sistem Koloid.

\subsubsection{Penentuan Tingkat Praktikalitas}

\subsubsection{Kemudahan Penggunaan.}

Berdasarkan hasil analisis data didapatkan nilai Momen Kappa dari uji praktikalitas media Permainan Kartu Kimia oleh guru dan peserta didik, yaitu 0,88 dan 0,80 . Hal ini menunjukkan Permainan Kartu Kimia sudah praktis dari aspek kemudahan penggunaannya. Permainan Kartu Kimia memiliki petunjuk penggunaan yang jelas dengan bahasa yang mudah dimengerti, gambar yang digunakan jelas, memiliki ukuran dan jenis huruf yang mudah dibaca, ukuran kartu yang praktis dan mudah dibawa, dapat digunakan berulang kali, tidak memerlukan biaya yang mahal, serta tidak memerlukan pelatihan khusus untuk menggunakannya.

\subsubsection{Efisiensi Waktu.}

Berdasarkan hasil analisis data didapatkan nilai Momen Kappa dari uji praktikalitas media Permainan Kartu Kimia oleh guru dan peserta didik yaitu 0,88 dan 0,80. Artinya media Permainan Kartu Kimia efisien jika digunakan pada saat proses pembelajaran di sekolah. Waktu yang dapat digunakan untuk Permainan Kartu Kimia ini adalah maksimal 90 menit. Hal ini menunjukkan bahwa media yang dikembangkan telah memenuhi pada aspek efisiensi waktu latihan.

\section{SIMPULAN}

Penelitian pengembangan Permainan Kartu Kimia (C-Card) pada materi Sistem Koloid sebagai media pembelajaran dilakukan menggunakan model four-D (4-D) yang terdiri dari tahap define, tahap design, tahap develop, dan tahap dissesminate. Permainan Kartu Kimia yang dikembangkan memiliki tingkat validitas sangat tinggi serta tingkat praktikalitas tinggi berdasarkan empat fungsi media dan ciri-ciri dari media praktis.

\section{REFERENSI}

1. Sharon E Smaldino, Deborah L Lowther I D. Intructional Technology \& Media for Learning. Terjemahan (Arif Rahman). Jakarta: Kencana; 2012.

2. Susilana R, Riyana C. Media Pembelajaran: Hakikat, Pengembangan, Pemanfaatan dan Penilaian. Bandung: CV Wacana Prima; 2009.

3. UNESCO. Games Toys in The Teaching of Science and Technology. Paris: 1988.

4. Trianto. Model Pembelajaran Terpadu. Jakarta: Bumi Aksara; 2012.

5. Sadiman, A., Raharjo, R., Haryono A dan R. Media Pendidikan: Pengembangan dan Pemanfaatannya. Jakarta: PT Raja Grafindo Persada; 2012.

6. Arsyad A. Media Pembelajaran. Jakarta: PT Raja Grafindo Persada; 2002. 